\title{
The Impact of Internal Marketing on Employees' Performance in Private Jordanian Hospitals Sector
}

\author{
Sima Ghaleb Magatef ${ }^{1} \&$ Raed Ahmad Momani ${ }^{1}$ \\ ${ }^{1}$ Marketing Department, Faculty of Administrative and Financial Sciences, University of Petra, Amman, Jordan \\ Correspondence: Sima Ghaleb Magatef, Marketing Department, Faculty of Administrative and Financial \\ Sciences, University of Petra, P. O. Box 961343, Amman 11196, Jordan. E-mail: simaghaleb@hotmail.com
}

Received: December 31, 2015

Accepted: January 15, 2016 Online Published: February 25, 2016

doi:10.5539/ijbm.v11n3p129

URL: http://dx.doi.org/10.5539/ijbm.v11n3p129

\begin{abstract}
This study aims to identify the impact of internal marketing on the performance of employees in Jordanian private hospitals sector. This study was conducted on all employees of several administrative levels in this sector. The study also aims to find out the impact of independent variables namely, in-house training, incentives, rewards, internal communication, empowerment and culture of the organization, on the dependent variable, which is the performance of employees. To achieve the study objectives, data were collected through the selection of a random sample of workers in private Jordanian hospital sector from various levels. 450 copies of the designed questionnaire were distributed over the targeted sample group. However, only 333 copies of the questionnaire were recovered, and this is $74 \%$ of the total number of the distributed copies. The results show that the organization culture has strong impact on the employee's performance. This variable came first among other variables, followed by the variables about incentives and rewards regarding the impact on the dependent variable employees. On the other hand, the rest of variables showed weak impact on the dependent variable either due to lack of employee's interest, or the lack of their awareness regarding the importance of these variables and the need to apply them in order to improve the performance of employees and increase their efficiency and effectiveness at work.
\end{abstract}

Keywords: internal marketing, internal training, motivation and rewards, internal communication, empowerment, organization culture, performance employers

\section{Introduction}

Internal marketing in all companies has great importance, particularly in companies operating in the service sector. This is because workers deal directly with clients, especially the front-line employees. So, successful companies have to pay attention to internal marketing, which means that they should take care of staff by considering them as internal customers of the company. This is done by providing benefits and services, which in turn improves their performance.

The main objective of the internal marketing process aims to develop and prepare qualified personnel capable of keeping customers and taking care of them, satisfy them and make them continue with the company. As a result, this lead to the achievement of profitability and also to having qualified and efficient employees continuously, leading to increasing their loyalty and reducing labor turnover.

\subsection{The Study Problem}

To identify the nature and degree of internal marketing application by Jordanian private hospitals sector, and the impact of this on the employees' performance, as well as to answer a series of sub-questions stemming from the general question below:

- Is there impact for internal marketing on employees' performance in private Jordanian hospitals sector?

From this general question, a group of sub-questions stemmed. These sub-questions are as follows:

- Does the private Jordanian hospital sector have a clear understanding regarding the level of importance of internal marketing and its impact on employees' performance?

- Does hospital sector take care of employees and does it realize that they are considered as a part of the service they provide to clients? 
- Does hospital sector have concern regarding personnel training and developing employee's skills and abilities in order to provide better service to customers?

- Does the hospitals sector have interest reading the incentives and rewards system for workers in order to increase their effectiveness at work?

- Does hospital sector have interest in relations among employees by establishing internal communications among them?

- Does hospital sector have interest in the empowerment of employees by allowing them to participate in decision-making within the organization?

- Does the hospital sector have its own culture that supports employees' performance?

\subsection{Objectives of the Study}

The study mainly aims to show the impact of internal marketing on the performance of employees in private Jordanian hospitals sector, as well as identify other sub- objectives as follows:

1). Determine the reality of thinking adopted by workers towards this issue.

2). Show the importance of training and qualifying system for workers to increase their efficiency at work.

3). Determine the importance of incentives and rewards system to increase the effectiveness of employees.

4). Illustrate the importance of internal communication among employees within the organization.

5). Determine the importance of employees' participation in strategic decision-making of the organization.

6). Determine the organization culture and the level of its contribution in improving employees' performance.

7). Show the extent of importance of the application of internal marketing and its components to improve the performance of employees.

8). Provide a set of recommendations and suggestions on internal marketing.

\subsection{Importance of the Study}

The importance of the study revolves around several concepts. First of all, This study is one of few studies conducted in Jordan about the impact of internal marketing on employees' performance in private Jordanian hospitals sector. The study also tries to identify the internal marketing elements affecting employees' performance. Furthermore, the study recognizes the role played by the internal marketing in its impact over employees' performance. Finally, the study comes up with a set of suggestions and recommendations that will help improve employees' performance.

\subsection{Study Model}

Independent Variables

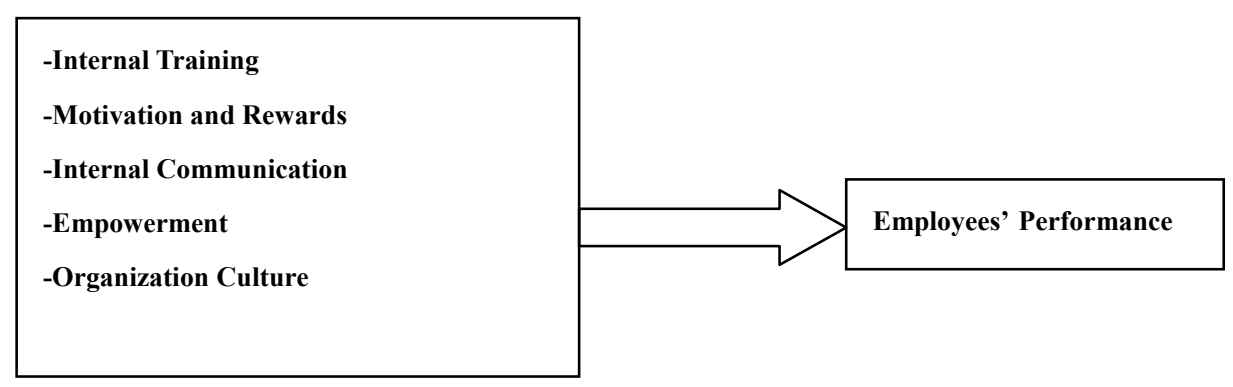

\subsection{Study Hypotheses}

Based on the study model and problem, the following general hypothesis was drafted:

Ho: there is no statistically significant effect for the application of internal marketing on employees' performance in private Jordanian hospitals sector.

Ha: there is statistically significant effect for the application of internal marketing on the employees' performance in private Jordanian hospitals sector.

A group of sub-hypotheses are derived from this main general hypothesis. 
- The first sub-hypothesis:

Ho: there is no statistically significant effect for internal training on employees' performance in private Jordanian hospitals sector.

Ha: there is statistically significant effect for internal training on employees' performance in private Jordanian hospitals sector.

The second sub-hypothesis:

Ho: there is no statistically significant effect for incentives and bonuses on employees' performance employees' performance in private Jordanian hospitals sector.

Ha: there is statistically significant effect for incentives and bonuses on employees' performance in private Jordanian hospitals sector.

The third sub-hypothesis:

Ho: there is no statistically significant effect for internal communication on employees' performance in private Jordanian hospitals sector.

Ha: there is statistically significant effect for internal communication on employees' performance in private Jordanian hospitals sector.

The forth sub-hypothesis:

Ho: there is no statistically significant effect for empowerment on employees' performance in private Jordanian hospitals sector.

Ha: there is statistically significant effect for empowerment on employees' performance in private Jordanian hospitals sector.

The fifth sub-hypothesis:

Ho: there is no statistically significant effect for the organization culture on employees' performance in private Jordanian hospitals sector.

Ha: there is statistically significant effect for the organization culture on employees' performance in private Jordanian hospitals sector.

\section{Literature Review}

Ghasemi (2014), the role of internal marketing in improving the quality of health services, private institutions. Addressed the internal marketing term, and tried to clarify its role on the quality of health services, which is achieved by the application of the study on private health institutions. For this purpose, (140) questionnaire were distributed, 60 of which were distributed over a sample of workers in these institutions, where 50 of them were recovered. Similarly, (80) questionnaires on a sample of patients of these institutions were distributed and all of them were recovered. This study showed that there was no interest in internal marketing as a philosophy despite the fact that there are some practices of some activities. The results also showed a positive correlation between internal marketing and the quality of services provided. The study concluded that improvement of the quality of health services requires the need to adopt the concept of internal marketing by these institutions, which can be done through paying enough to training programs and incentive systems.

A study by labd and Ryan (2013) entitled "The impact of internal marketing on the performance of employees in civil society institutions", showed that the analysis of relationship and impact between internal marketing procedures represented by service culture, internal training and dissemination of marketing information to employees on the performance of employees in civil society, which has become one of the vital and contemporary issues as interest in internal marketing in civil society organizations increased at the present time, especially after the emergence of the role and importance of internal marketing to get personnel of high capabilities and skills who are able of assume responsibility and provide high-level services of quality to customers. And the limited studies on the relations between these variables, especially in the Gaza Strip environment, the researcher sought to address these variables in this study in order to reach and impact study of the relationship between them.

Chen (2013), How internal marketing can cultivate psychological empowerment and enhance employee performance. Examined the impact of psychological empowerment on employee loyalty, satisfaction, and task performance with survey data from 617 employees of a petrochemical company in China. Results based on a structural equation model showed that psychological empowerment had a significant positive effect on both 
employee loyalty and task performance, which was partially mediated by employee satisfaction. In addition, we found that psychological empowerment was significantly and positively influenced by each dimension of internal marketing.

Iuliana and Cetina (2012), Employee Satisfaction Measurement-Part of Internal Marketing, defined that Since 1980 service companies have realized that standards and technology are essential for the successful implementing of the adopted strategy، but not enough. Without employees with the proper attitude, knowledge and skills, strategy cannot generate the desired results.

Great service companies highlight that employees (front-line employees) are responsible for the implementation of the service strategy, their satisfaction and loyalty having a direct and strong influence on the satisfaction and loyalty of the customers.

In this context, this paper aims to highlight the importance of employees in delivering reliable services, as well as how to measure employee satisfaction levels.

Regarding the employee satisfaction measurement, this paper presents primary marketing research conducted on the front-line employees of the Romanian Commercial Bank of Sibiu.

Results show that employees are generally satisfied, but the interaction with the customer is still affected by lower motivation, lack of quality standards from the customer's perspective and their limited involvement in decision making.

The study (Ahmad, 2012), examine "the impact of internal marketing on job satisfaction and organizational commitment of the teaching hospitals in Kingdom of Saudi Arabia". The independent variables are internal marketing factors were represented by these variables namely selection and appointment, training and development, organizational support, incentives and motivation, and retention policy. The dependent variables were represented by job satisfaction and organizational commitment. A structured questionnaire was distributed to a sample of 250 physicians representing all of the teaching hospitals in Saudi Arabia. This study has used the multiple regression analysis to show the impact of internal marketing on job satisfaction and organizational commitment. The research's findings showed that internal marketing (selection and appointment, training and development, organizational support, incentives and motivation, and retention policy) had a positive effect on Saudi teaching hospitals physicians' job satisfaction, and organizational commitment. This research will make a positive contribution in the direction of internal marketing factors and its impact on physicians' job satisfaction and organizational commitment in Saudi teaching hospitals in KSA.

The Purpose of the Study (Acar, Seker, Bayram, \& Acar, 2012), "The effect of internal marketing on the performance of employee and the mediating role of organizational commitment", was to investigate the effect of internal marketing on the performance of employee and the mediating role of organizational commitment. Data collected through the questionnaires from the administrators of 19 private hospitals in 6 provinces. In order to test the hypothesis correlation and regression analysis were conducted. The results of the research clearly show that there are significant relationships between internal marketing practices and employee performance and organizational commitment. Besides, organizational commitment has a partial mediating role. Consequently, the research is supposed to contribute greatly to the literature and administrators facing customer in need of different services resulting from changing time and values in terms of organizational commitment and effective applications of internal marketing that increase employee performance.

This Paper (Zaman, Javid, Arshad, \& Bibi, 2012) "Impact of internal marketing on market orientation and business performance", investigate the impact of internal marketing on commercial banks' organization commitment, market orientation, and business performance. Data collection from 12 commercial banks of Pakistan was targeted. Quantitative approaches were used for data collection from 500 bank employees and effective data was further analyzed by using inferential techniques on SPSS 18.00. The findings of the study suggested that internal marketing programs had a significant impact on employees' commitment, their market orientation and overall profitability of the firm. In addition, the mediating relationship of organization commitment with internal marketing and market orientation was not supported. The paper investigates the associations by adding a cultural value aspect of Hofstede suggested by Awwad and Agti (2011), and study is extended by incorporating element of business performance and market orientation in a single study. The findings support the originality of the work. Additionally, parsimonious aspect is followed by taking the only mediating variable i.e. organization commitment. Lastly, this paper is one of few papers that focus on internal marketing in Pakistani banking industry adds to its originality.

This study (Doost \& Hooshmand, 2012), "The effect of internal marketing and organizational commitment on 
banks' success", provides a model to explore the effects exerted by internal marketing, and employees organizational commitment as antecedents of market orientation over Iranian private banks' financial performance with regard to mediating role of market performance in these banks. We designed a frame work to show how private banks use internal marketing, market orientation and employees organizational commitment to increase their market and organizational performance. Empirical findings confirmed that internal marketing, organizational commitment and market orientation have positive direct and indirect effects on bank's both market performance (customer satisfaction and customer loyalty) and financial performance. Iranian private banks should convert internal marketing as a strategy into their core operations and systems to meet employees' demands and the banks' goals. This conversion shall make employees show their sincere organizational commitment that is beneficial for the banks' market orientation which has a significant impact on market and financial performance. The paper introduces a new perspective of the interactions that take place between marketing, organizational behavior concepts which affect market and financial performance. This paper is one of few papers that focus on internal marketing in Iran banking sector.

The study (Fernando, 2012), "Impact of internal marketing on operational performance: An empirical study in low cost carrier industry", examine the link between internal marketing and operational performance. Two hundred nine questionnaires those are usable for the analysis. The results show that training and development, senior leadership and empowerment were significantly associated with operational performance. Thus, there was no evidence where strategic rewards and internal communication work well on operational performance. The paper results indicate that low cost carrier managers should pay attention to upgrade employee's knowledge in regular basis, as it is a market requirement, especially in the use of labor - saving technology to maintain competitiveness.

The study (Hadipranowo, 2012), "Influence of internal marketing towards organizational performance with mediating role of organizational competences in not for profit organizational AIESEC", empirically evaluates the internal marketing as a framework for implementing marketing strategies. Internal marketing variables that are used in this study are strategic rewards, senior leadership, internal communication and training and development as an independent variable. Dependent variable in this research is the organizational performance with the organizational competencies organization involves as intervening variable that mediates internal marketing to organizational performance.

Primary data were collected, using questionnaires of 56 respondents who are active members who worked on PBOX HIV / AIDS in Indonesia AIESEC. Two regression models were used to analyze the data.

The results of the first model regression analysis showed that all variables of internal marketing (strategic rewards, senior leadership, internal communication and training and development) affect the competence of the organization significantly. The second model of regression analysis showed that organizational competences affect organizational performance significantly.

The analysis shows that internal marketing fourth variables influence organizational performance variable along with the organizational competences variable. However, training and development the variable of is the one that has the strongest influence. It can be concluded that if there is a better training and development and more consistent program, then the strategy of internal marketing can be successful and will perform well.

The study by Altai (Tai, 2012), analysis of collaborative relationship between intelligent marketing and internal marketing and their impact on employees' satisfaction in the AlSelsela Hotels: a case of Oman from the perspective of workers in these hotels. Deliberate appropriate sample of 378 workers working in human resources, marketing and sales, information technology, finance and front office departments in hotels was selected.

The relationship between internal marketing procedures and satisfaction of employees in the hotels under study was tested in the presence of intelligent marketing, and using the statistical program (Amos v18) to analyze the study questionnaire connected with independent, intermediate and dependent variables.

Results of the analysis showed the existence of clear impact of internal marketing procedures on staff satisfaction in light of the application of intelligent marketing mechanisms in the Selsela Hotels. The study recommended that management of the Hotels understudy should work to enrich marketing information and deal morally with it, and they need to distribute information and make it accessible to workers so that Hotel management can take appropriate decisions, in addition to the optimal use of information technology to achieve mutual benefit, not only for workers in the hotels and their customers, but it is necessary to be distributed them to suppliers and brokers and even hotels public. 
The study by (Hawwaorh, Shqaiqat, \& Sbaih, 2011) entitled "the impact of internal marketing on customer loyalty through job satisfaction: Nablus and Jenin cities", addressed the analysis of the relationship and impact of internal marketing procedures represented by several elements including job tasks knowledge, training programs, appropriate remuneration, communication within the organization, teamwork, and the dissemination of marketing information relating to workers performance, and it dealt with job satisfaction through working conditions, the nature of supervision, incentives and rewards system, promotion opportunities, social status, guarantees stability, safety, job security, doing the job duties, flexible hours of work, and convenient organizational climate. It also addressed customer loyalty from the perspective of workers as represented in paying attention and taking care to customers, understanding customers' needs and meet them as soon as possible, which have become among the vital and contemporary themes, as attention to internal marketing in organizations increased, particularly in service organizations at the present time, especially after the emergence of the role and importance of internal marketing to get the capable individuals of high skills and able to assume responsibility and provide high-quality level of service to customers.

\section{Variables Measurement}

\subsection{Internal Training}

It is the administrative and organizational efforts that aim at improving the ability of individual to perform a specific job or to do a specific role at the facility where he works (Abu Alsaud, 2004, p. 80). It is also defined as a set of procedures and processes that aim at providing and developing the skills and knowledge of individuals working in a given organization in order to raise the level of their performance, which will achieve positive results for the organization and employees (Lebd \& Ryan, 2013, p. 24).

This variable shall be measured in the questionnaire in questions 1-12.

\subsection{Incentives and Rewards}

They are methods of developing personnel capacities, which will increase their performance in quality and quantity, or at least one of them, and urge them to do their jobs faithfully. These are among external influences that affect the individual's behavior by satisfying his needs, and thus motivating him to perform his job in a better way. (AlKalaldeh, 2013, p. 94)

This variable will be measured in the questionnaire in questions 13-23.

\subsection{Internal Communication}

It includes all formal and informal communications that take place in the organization at all job levels. (Aisha, 2014, p. 12).

Communication has an important role in organization since it gives evidence that organization effective communication strategies are usually successful. Moreover, internal communication is the exchange of information and ideas within organization, and it is about creating an atmosphere of respect among all employees within the organization. (Hadipranowo, 2012, p. 41)

This variable will be measured in the questionnaire in questions 24-30.

\subsection{Empowerment}

It is represented by workers' participation in decision making, giving them more freedom in work, more authority, self-supervision, not to mention supporting their capabilities and skills, and finally providing them with enough resources and suitable environment (Aisha, 2014, p. 12)

This variable shall be measured in the questionnaire in questions 31-38.

\subsection{Organization Culture}

This means all the traditions, values, customs and characteristics that form the general atmosphere of the service, and have impact on workers. This is because the culture and internal atmosphere of the organization affect workers and shape up their personalities, values and attitudes, (Lebd, Ryan, 2013, p. 24).

This variable shall be measured in the questionnaire in questions 31-38.

\subsection{Employees' Performance}

Performance indicates the level of achievement of work of the worker, and how he achieves his job requirements. The degree of achievement and completion of tasks of the job are discussed in (Albornouti, 2000, p. 219).

This variable shall be measured in the questionnaire in questions 48-56. 


\section{Theoretical Frame Work}

\subsection{Introduction}

Traditionally, marketing concentrates on the exchange operations between the organization and the customer. However, the nature of the role played by the organization employees in determining the quality level and the effect of the level of the client's satisfaction on the marketing has drawn attention to another form of relation that can take place between the organization and its employees. In view of the special features that are unique to the services, the traditional methods of practices of external marketing are considered of limited effect when applied in the service field based on the material goods, where workers performance in the service field represents the product purchased by the external customer and as it is one of the main tools used by the organization to achieve excellence in market. As a result, modern marketing concept emerges when workers within the organization become interested in the so-called internal marketing.

Since internal marketing is more important in service companies, the hospital sector has been selected due to the lack of research of interest in this sector in Jordan.

\subsection{Internal Marketing}

Internal marketing concept was presented for the first time more than thirty years ago, specifically by Perry and others in 1976 as one of the solutions to the problems relating to the provision of high quality services characterized by symmetry and harmony at the same time. (Abu Alnaja, 2012, p. 149).

Internal marketing did not occur separately and independently away from the marketing concept in general. Marketing concept is based on the process of exchange in the market, and the trend towards the consumer, as well as integration between the organization functional activities, and orientation towards profit in the long term. It will become a basic tool that enables the organization to rely on it to apply any concept or sub-marketing philosophy, such as internal marketing, if applied properly. While organizations focus on exchange operations with external customers in order to achieve a significant position in the market where they are active. Based on this, we find that the role played by staff working in the organization, especially those in service companies, in determining the competitive feature, quality level and customer satisfaction, has led organizations to focus attention on another form of exchange. This can occur between the organization and its workers. This has led to the emergence of a modern marketing concept known as the internal marketing focusing on employees within the organization. (Abu Alnaja, 2008, p. 130)

He defined internal marketing as "employees are considered as internal customers and jobs as internal products that should be designed to satisfy the desires and needs of internal customers in the direction of achieving the organization's objectives."

Internal marketing concept also refers to the policies and programs directed to staff in the organization (internal customers) in order to achieve high level of satisfaction among them, which in turn can lead to raising the level of quality of service provided to external customers (Lovelock \& Wirtz, 2006, p. 56. )

\subsection{Importance of Internal Marketing}

Internal marketing is of great importance in satisfying the needs and desires of workers and achieving the organization's objectives since it achieves job satisfaction for workers and provide an internal environment that supports the morale and develop ways of positive behavior among individuals in the interest of the organization. The following is an explanation of the importance of internal marketing of the organization and workers.

\subsection{The Importance of Internal Marketing for the Organization}

Internal marketing is considered a management approach aiming to reach customers by developing and motivating workers in the organization to carry out their duties in the best possible way when dealing with customers by applying management and quality philosophy in the performance of services by all members of the organization in a way that achieves quality and customer satisfaction. (Omar Aljariri, p. 55).

This means that adopting internal marketing methods and philosophy in the organization is the way, through which the organization reaches its external markets, and it is the tool by which the organization promotes its competitive position in these markets. This is reflected positively on the organization's performance, profitability and objectives (Althmour, 2005, p. 343).

\subsection{The Importance of Internal Marketing for the Employees}

Employees get many benefits and advantages as a result of the application of internal marketing programs. The most important of these benefits are the achievement of satisfaction and sense of stability among workers. These 
are achieved by considering their requirements, needs and meeting them since these are among the most significant factors contributing to their satisfaction, in addition to developing and improving the worker's performance level. The employee is the first one who shall benefit from internal marketing programs because they aim at providing all appropriate conditions aiming to improve his performance, and thus increasing his pride in the work he is doing.

Likewise, the drastic improvement of relations between workers, whether they are in the same administrative level or in a higher or lower level, results in the sense of affiliation to the organization, which is a positive side for the employee.

Finally, the employee's feeling about the job he is doing contributes to the achievement of the common objectives of the organization and workers, thus changing his view about the meaning of work. This makes the employee seeks to achieve self-realization and excellence at work and satisfies his higher needs rather than just the physical ones only.

\section{Objectives of Internal Marketing}

Internal marketing goals are included in external marketing objectives and in the overall objectives of the organization. Internal marketing aims at managing employees and strengthening their enthusiasm in order to improve their performance and behavior in a manner that ensures the success of internal and external programs carried out by the organization. Generally, internal marketing aims to achieve the following objectives (Dish, 2002, p. 408).

First, internal marketing help employees understand and accommodate to the organization's mission and objectives, systems and working methods applied within the organization. Second, it motivates employees and raises their enthusiasm towards the achievement of their jobs efficiently, changing their attitudes and behavior with customers, especially those who are in direct contact with. The third objective of internal marketing is that staff will be able to Acquire more commitment towards plans, strategies and culture of the organization. Moreover, employees will be able to manage changes by moving from the way they used to work in into another way of work until we achieve success. (Percy \& Morgane). Furthermore, this will help build an organizational culture based on customer service and quality of service, leading to maintaining quality standards in the delivery of services, (R. Norman).

\subsection{Internal Marketing Dimension}

Indeed, internal marketing concept is not just the philosophy the organization should adopt, but rather the philosophy and activities that require effort and work leading to the adoption of the concept of internal marketing and applying it on the ground in the organization. When defining internal marketing, many researchers have tried to develop a range of activities and procedures capable of the application of this concept in organizations. Some researchers focused on the stimulus, internal communication, training, development, empowerment of employees, leadership, coordination, organizational culture, integration between jobs, and other activities that most researchers believe they represent elements or components that should be included in internal marketing application. However, by looking at most of the previous studies and published thesis, it is evident that there are some agreed-upon dimensions by most researchers, which are among the most important activities that must be practiced within the organization. The most important of these are training workers, and providing them with skills and experience that make them able to deal well with customers, where the workers are considered the supplementing party of any organization when customers are in contact with them. So, the image of the organization begins with each member of the organization personnel. In contrast, it is also reflected in attitudes and behavior towards the organization. In order that the organization becomes successful in this regard and be able to give a clear picture of its mission and objectives through employees' conduct and behavior, the right way and content is to provide workers with the skills and capabilities required for the proper performance of their jobs and their activities as well. This is because the manner of workers' handling their jobs, the way they talk and address, expressions of their faces, their personality will positively affect the service provided to external customers, especially if this behavior is consistent with the organization's policy. The effectiveness of the training is measured on the basis of improvement of efficiency and capacity through the education process, which is essential if the skills, knowledge and attitudes were not good before the training process. If these features developed and the worker acquired high efficiency, it means that the training was effective and influential because the training process must be synchronized with the education process because without education and the acquisition of experience, there will be no role for the training. Amongst the significant matters that fall under the responsibility of the service organization management is to continuously enhance information and skills gained during the training process on the part of workers. (Lebd \& Ryan, 2013, pp. 
26-28).

-Provision of incentives and rewards: These form the stimulus in addition to its contribution to increasing revenues accruing to the organization when the incentives systems are efficient, which is done through raising the production efficiency of the staff members.

Moreover, incentives and rewards reduces the size of the labor force required by the organization through the contribution of incentive systems that blow up workers' energy and capabilities, leading to benefiting from them as much as possible.

It also improves the physical, psychological and social status of the individual, and leads to the achievement of link between the individual's self-interests and that of his organization.

Furthermore, incentives and rewards reduce the cost of production towards innovation, development, adoption of modern methods that reduce time and raw materials spent in production to achieve a state of satisfaction among personnel due to incentives. So, they will be the solution to many administrative problems in the presence of high cost rates and the rate of labor turnover (Alkalaldeh, 2012, pp. 95-96).

Hence, it is clear that incentives and rewards system achieves economic goals of the organization through the increase of the organization productivity and the optimal use of components, in addition to the achievement of moral goals of the individual that enable the employee to work enthusiastically in appropriate atmosphere, and help him contribute to improving his performance.

\subsection{Staff Performance}

The concept of performance was subject to study and research early because of it is importance that imposed the need to focus on it by putting forward alternative concepts replacing it, and by researchers' tries aiming at defining this concept accurately and studying the factors that affect, specify, and measure it.

Performance indicates the level of achievement of work constituting the worker's job and the way by which the individual worker achieves his job requirements. Staff performance has been defined as "the degree of achievement or completion of tasks constituting the job". This definition reflects how the individual satisfies or achieves his job requirements (Albarnouti, 2000, p. 219).

There is a difference between the concept of performance and another concept which is not synonymous to performance, which is the concept of productivity. Usually productivity is usually associated with individuals whose jobs are related to machines and tools, where $s$ the volume of production achieved during a certain period of time can be calculated, as well as the materials used in production and other things by using certain units of work, such as the number of workers, time required for the production. This might be reflected in the number of workers needed for production and similar things. This means that the concept of performance is broader than that of productivity considered in various industrial and non-industrial sections.

Understanding performance and measuring it is the goal of workers, and it is the goals upon which administrative decisions are based, which contribute to the achievement of the organization objectives, whether those related to the individual himself, his career or to the organization. (Felt, Ryan, 2013, p. 30).

\subsection{Determinants of Employees' Performance}

The worker's performance is the clear effect of his efforts that begin with the effort exerted and abilities and realization of the role or tasks. This means that performance in a particular situation can be seen as a result of overlapping relationships between effort, capacity, and awareness.

To achieve a satisfactory level of performance, there should be a minimum level of proficiency in each component of performance, in the sense that when individuals exert super efforts and have superior capabilities, but they do not understands their roles, the performance will not be acceptable from the point of view of others. In spite of large efforts at work, this work was not directed in the right way. In the same way, the individual who works very hard and understands his work, but lacks the capacity, the level of his performance will usually by evaluated as low. There is another possibility where the individual may has the necessary capacity and understanding of the role he is doing, but he is lazy and does not exert big effort at work. Such an individual's performance will be also low. Naturally, the individual performance might be good in one of the performance components and weak in another (Lebd \& Ryan, 2013, p. 33).

As shown previously, it is clear that it is not easy to get excellent facilities that deal with global changes, adapt and respond to them, but this can be done by keeping up with applied modern methods to evaluate the performance of the human element by depending on designing systems for human performance evaluation (Abu Saud Mohammed, 2004, p. 79). 
This study focuses on the most important internal marketing dimensions affecting the employees' performance in Jordanian private hospitals sector, which is one of the most important sectors in Jordan.

\section{Study Methodology}

\subsection{Data Instrument}

To achieve the goal of this study, the focus will be placed on finding primary data by building a questionnaire (Instrument) to collect data from the targeted sample.

The questionnaire consists of two parts, the first of which is about demographical factors, and the second one is about the impact of internal marketing on performance employees in private Jordanian hospitals. The instrument relies on a five-point of Likert Scale, representing a range from 1 (strongly disagrees 0 to 5 (strongly agree), in order to measure the impact of internal marketing on employees' performance in private Jordanian hospitals

\subsection{Study Population and Sample}

The study population: all workers in Jordanian private hospitals sector

\subsubsection{Sample size}

The study sample represented by the Jordanian private hospitals sector was chosen. The sample is determined to be random in order that all individuals have equal opportunity.

Questionnaires were distributed over 450 male and female employees from all sections of these hospitals at all administrative levels, namely the upper, middle, lower. 333 copies of the questionnaires were recovered, which is equivalent to $74 \%$ of the sample size.

\subsubsection{Description of the Study Sample}

The results of Table 1 show that most respondents to the study were males with an average of $56.2 \%$, and the age category is from $22-30$ years old amounting to $52.3 \%$ and that's because the majority of the employees of this sector their age range between (22-30), The majority of respondents are within the group who hold a bachelor degree at the average of $45 \%$, the married respondents are $50.8 \%$. From the level of middle management, the average is $55 \%$, where the majority of them have less than 3 years of experience, and where the income is from the income group less than 500 J.D monthly, the average is $52.3 \%$.

Table 1. Distribution of the study sample by demographic variables

\begin{tabular}{llll}
\hline & & Frequency & Percent \\
\hline \multirow{3}{*}{ Gender } & 1 & 187 & 56.2 \\
& 2 & 146 & 43.8 \\
& Total & 333 & 100.0 \\
Age & 1 & 174 & 52.3 \\
& 2 & 87 & 26.1 \\
& 3 & 34 & 10.2 \\
Education & 4 & 38 & 11.4 \\
& Total & 333 & 100.0 \\
& 1 & 99 & 29.7 \\
Material & 2 & 150 & 45.0 \\
& 3 & 40 & 12.0 \\
& 4 & 44 & 13.2 \\
& Total & 333 & 100.0 \\
Experience & 1 & 121 & 36.3 \\
& 2 & 169 & 50.8 \\
& 3 & 34 & 10.2 \\
& 4 & 9 & 2.7 \\
& Total & 333 & 100.0 \\
& 1 & 87 & 26.1 \\
& 2 & 183 & 55.0 \\
& 3 & 63 & 18.9 \\
& Total & 333 & 100.0 \\
& 1 & 129 & 38.7 \\
& 2 & 112 & 33.6 \\
& 3 & 40 & 12.0 \\
& 4 & 12 & 3.6 \\
\hline
\end{tabular}




\begin{tabular}{llll}
\hline & 5 & 40 & 12.0 \\
Total & 333 & 100.0 \\
Income & 1 & 174 & 52.3 \\
& 2 & 80 & 24.0 \\
& 3 & 14 & 4.2 \\
& 4 & 26 & 7.8 \\
& 5 & 39 & 11.7 \\
\hline
\end{tabular}

\subsection{Descriptive Statistics Analysis}

Table 2 shows that all of means of the questionnaire statements were in the high zone of approval. All the study variables means were high.

The internal training has the highest mean scores $\mathrm{M}=3.69$ with $\mathrm{S} . \mathrm{D}=0.67$, followed by organization culture $\mathrm{M}=$ 3.67 with $S . D=0.7$, then internal communication $M=3.62$ with $S . D=0.73$, motivation and rewards $M=3.61$ with $\mathrm{S} . \mathrm{D}=0.65$. And finally empowerment $\mathrm{M}=3.60$ with $\mathrm{S} . \mathrm{D}=0.69$.

Table 2. Mean and standard deviation for questionnaire statement and study variables

\begin{tabular}{|c|c|c|}
\hline & Mean & Std. Deviation \\
\hline a1 & 3.58 & 1.21 \\
\hline a2 & 3.51 & 1.02 \\
\hline a3 & 4.02 & 0.82 \\
\hline $\mathrm{a} 4$ & 3.77 & 1.10 \\
\hline a5 & 3.65 & 1.12 \\
\hline a6 & 3.83 & 0.99 \\
\hline a7 & 3.60 & 1.16 \\
\hline a8 & 3.74 & 1.14 \\
\hline a9 & 3.65 & 1.12 \\
\hline a10 & 3.61 & 1.09 \\
\hline a11 & 3.56 & 1.12 \\
\hline a12 & 3.73 & 1.10 \\
\hline a13 & 3.53 & 1.15 \\
\hline a14 & 3.51 & 1.13 \\
\hline a15 & 3.71 & 1.02 \\
\hline a16 & 3.59 & 1.11 \\
\hline a17 & 3.54 & 1.17 \\
\hline a18 & 3.58 & 1.10 \\
\hline a19 & 3.70 & 1.03 \\
\hline a20 & 3.63 & 1.07 \\
\hline $\mathrm{a} 21$ & 3.69 & 0.97 \\
\hline a22 & 3.66 & 1.12 \\
\hline $\mathrm{a} 23$ & 3.58 & 1.17 \\
\hline a24 & 3.71 & 1.01 \\
\hline a25 & 3.66 & 1.08 \\
\hline a26 & 3.64 & 1.11 \\
\hline a27 & 3.53 & 1.13 \\
\hline $\mathrm{a} 28$ & 3.58 & 1.18 \\
\hline a29 & 3.57 & 1.11 \\
\hline
\end{tabular}




\begin{tabular}{|c|c|c|}
\hline $\mathrm{a} 30$ & 3.65 & 1.14 \\
\hline a31 & 3.57 & 1.17 \\
\hline $\mathrm{a} 32$ & 3.62 & 1.07 \\
\hline a33 & 3.62 & 1.09 \\
\hline a34 & 3.59 & 1.11 \\
\hline a35 & 3.61 & 1.16 \\
\hline a36 & 3.50 & 1.19 \\
\hline a37 & 3.68 & 1.05 \\
\hline a38 & 3.63 & 1.08 \\
\hline a39 & 3.77 & 1.08 \\
\hline $\mathrm{a} 40$ & 3.73 & 1.04 \\
\hline $\mathrm{a} 41$ & 3.59 & 1.14 \\
\hline $\mathrm{a} 42$ & 3.65 & 1.11 \\
\hline $\mathrm{a} 43$ & 3.65 & 1.09 \\
\hline $\mathrm{a} 44$ & 3.68 & 1.06 \\
\hline $\mathrm{a} 45$ & 3.65 & 1.14 \\
\hline $\mathrm{a} 46$ & 3.62 & 1.14 \\
\hline $\mathrm{a} 47$ & 3.67 & 1.06 \\
\hline b1 & 3.67 & 1.15 \\
\hline $\mathrm{b} 2$ & 3.51 & 1.11 \\
\hline b3 & 3.38 & 1.25 \\
\hline b4 & 3.44 & 1.19 \\
\hline b5 & 3.76 & 1.02 \\
\hline b6 & 3.65 & 1.15 \\
\hline b7 & 3.64 & 1.07 \\
\hline $\mathrm{b} 8$ & 3.48 & 1.16 \\
\hline b9 & 3.59 & 1.17 \\
\hline Internal Training & 3.69 & 0.67 \\
\hline Motivation and Rewards & 3.61 & 0.65 \\
\hline Internal Communication & 3.62 & 0.73 \\
\hline Empowerment & 3.60 & 0.69 \\
\hline Organization Culture & 3.67 & 0.70 \\
\hline internal marketing & 3.64 & 0.51 \\
\hline Employees' Performance & 3.57 & 0.73 \\
\hline
\end{tabular}

\subsection{Statistical Analysis}

6.4.1 Results of the Study: Hypothesis Testing

The results of the first question stipulating the level of internal marketing from employees' point of view?

To answer this question, means and standard deviations of employees, (the study sample) responses were calculated regarding all dimensions of internal marketing which are Internal Training, Motivation and Rewards, Internal Communication, Empowerment, Organization Culture. 
Table 3. Means, standard deviations of study sample responses

\begin{tabular}{llllll}
\hline No. & Scale & Mean & Std. Deviation & Rank & Degree \\
\hline 1 & Internal Training & 3.69 & 0.67 & & High \\
5 & Organization Culture & 3.67 & 0.70 & 4 & High \\
3 & Internal Communication & 3.62 & 0.73 & 2 & High \\
2 & Motivation and Rewards & 3.61 & 0.65 & 1 & High \\
4 & Empowerment & 3.60 & 0.69 & 3 & High \\
Internal marketing & 3.64 & 0.51 & & High \\
\hline
\end{tabular}

It is obvious from Table 3 that the level of internal training is high with a mean of (3.69) included in the statistical standard used in this study (from 3.40-less than 4.20), where the estimates of the study on internal marketing dimensions ranges between (3.60) and (3.69). It can be seen from table 3 that all dimensions are with high level, and their order is internal training, organization culture, internal communication, motivation and rewards, empowerment respectively.

The results of the second question stipulating the level of employees' performance from employees' point of view?

To answer this question, means and standard deviations of employees' responses (the study sample) are calculated regarding all employees' performance parts, which were 3.57, 0.73 respectively, where the mean included in the statistical standard used in the study (3.40-less than 4.20) indicates medium level of marketing.

The results of the third question stipulating internal marketing impact on employees' performance?

To answer this question, the impact of all dimensions of internal marketing was examined, and based on this the following null hypotheses stemmed.

First, the first null hypothesis states that there is no impact for internal training on employees' performance, the second null hypothesis states that there is no impact for internal communication on employees' performance, the third null hypothesis states that there is no impact for motivation and rewards on employees' performance, the fourth null hypothesis states that there is no impact for empowerment on employees' performance, and finally, fifth null hypothesis states that there is no impact for organization culture on employees' performance.

\subsubsection{Pre-Test Analysis}

To make sure of the quality of data and its suitability, using multiple regression analysis and other statistical analysis is required to test hypotheses, and so some pre-test analysis has been undertaken.

- Testing the independence of independent variables

Pearson correlation coefficients matrix was calculated between every two independent variables, in order to detect the presence of linear correlation between the independent variables. 
Table 4. The correlation coefficients matrix (Person) between every two independent variables (internal training, motivation and rewards, internal communication, empowerment organization culture)

\begin{tabular}{|c|c|c|c|c|c|}
\hline & & $\begin{array}{l}\text { Internal } \\
\text { Training }\end{array}$ & $\begin{array}{l}\text { Motivation } \\
\text { and Rewards }\end{array}$ & $\begin{array}{l}\text { Internal } \\
\text { Communication }\end{array}$ & Empowerment \\
\hline \multirow{3}{*}{$\begin{array}{l}\text { Motivation } \\
\text { Rewards }\end{array}$} & Pearson Correlation & $.590 * *$ & & & \\
\hline & Sig. (2-tailed) & .000 & & & \\
\hline & $\mathrm{N}$ & 333 & & & \\
\hline \multirow{3}{*}{$\begin{array}{l}\text { Internal } \\
\text { Communication }\end{array}$} & Pearson Correlation & $.552 * *$ & $.423 * *$ & & \\
\hline & Sig. (2-tailed) & .000 & .000 & & \\
\hline & $\mathrm{N}$ & 333 & 333 & & \\
\hline \multirow{3}{*}{ Empowerment } & Pearson Correlation & $.546^{* *}$ & $.415 * *$ & $.568 * *$ & \\
\hline & Sig. (2-tailed) & .000 & .000 & .000 & \\
\hline & $\mathrm{N}$ & 333 & 333 & 333 & \\
\hline \multirow{3}{*}{ Organization Culture } & Pearson Correlation & $.331 * *$ & $.400 * *$ & $.283 * *$ & $.365^{* *}$ \\
\hline & Sig. (2-tailed) & .000 & .000 & .000 & .000 \\
\hline & $\mathrm{N}$ & 333 & 333 & 333 & 333 \\
\hline
\end{tabular}

**. Correlation is significant at the 0.01 level (2-tailed).

It is noted in Table 4 that most of the connectivity relations between the study dimensions are positive and moral (significant), and statistically significant at the level of the statistically significant indicator $(\alpha=0.01)$, where it was found that the strongest correlation value was (0.590) between the internal training dimension and that of motivation and rewards. So, it can be judged that there is no perfect correlation between independent variables.

\subsubsection{Linear Correlation Test (Multicollinearity)}

Linear correlation test is used in order to make sure that there is no high correlation between independent variables. This is done based on the test of inflation coefficient of variation (VIF), and variation allowed test (Tolerance) for each variable of independent variables, where independent variables of the model must be independent from each other. To make sure of that purpose, we use these two tests which are seen as one of the methods used to get rid of linear diversity problem, not to mention that that inflation variation coefficient of the value (10) must be considered, and the value of the variation test permitted must be bound to greater than (0.05). By calculating previous transactions for all independent variable, the results obtained are listed Table 5.

Table 5 the results of the inflation coefficient of variation test (VIF) and variation allowed test (Tolerance). (Internal Training, Motivation and Rewards, Internal Communication, Empowerment Organization culture)

Table 5. Collinearity statistics

\begin{tabular}{lll}
\hline & Collinearity Statistics & VIF \\
\hline Internal Training & Tolerance & 1.995 \\
Motivation and Rewards & .501 & 1.679 \\
Internal Communication & .596 & 1.701 \\
Empowerment & .588 & 1.741 \\
Organization Culture & .574 & 1.264 \\
\hline
\end{tabular}

It is noted in Table 5 that the values of the inflation coefficient of variation values test (VIF) for all independent variables is less than (10), and the values range between (1.264) and (1.995). The value of variation coefficient allowed test (Tolerance) for all independent variables is greater than $(0.05)$, and the value ranges between $(0.501)$ and $(0.791)$. Therefore, it can be said that there is no high correlation problem between independent variables. This indicates the existence of statistically significant correlation between the independent variables listed in the table (correlation), and this enhances the possibility of using it in this model. After the inclusion of the four 
independent variables in a multiple linear regression analysis (Internal Training, Motivation and Rewards, Internal Communication, Empowerment Organization Culture), using the (STEPWISE) method, which is used to find out which of the four independent variables have statistically significant effect on the dependent variable (Employees' Performance), as well as knowing the percentage of that Effect, if any.

-Variation analysis (ANOVA)

After the entry of independent variables (Internal Training Motivation, Rewards, Internal Communication, Empowerment, Organization Culture), variation analysis of independent variables was calculated, which are shown in Table 6.

Table 6. Results of variation analysis (ANOVA) to check the strength and morale the multi-linear regression form

\begin{tabular}{lllllll}
\hline Model & & Sum of Squares & df & Mean Square & F & Sig. \\
\hline 1 & Regression & 64.318 & 1 & 64.318 & 185.605 & $.000^{\mathrm{b}}$ \\
& Residual & 114.703 & 331 & .347 & & \\
& Total & 179.021 & 332 & & & \\
\hline 2 & Regression & 65.847 & 2 & 32.924 & 96.001 & $.000^{\mathrm{c}}$ \\
& Residual & 113.174 & 330 & .343 & & \\
& Total & 179.021 & 332 & & & \\
\hline
\end{tabular}

a. Dependent Variable: Performance Employers'.

b. Predictors: (Constant), Organization Culture.

c. Predictors: (Constant), Organization Culture, Motivation and Rewards.

It is noted in Table 6 the existence of two statistically significant variables only, which are organization culture, motivation and rewards, where their value is $(\mathrm{F}=96.001)$ with statistically significant value of $(0.000)$, which is less than the level of the statistically significant

Value $(\alpha=0.05)$, indicating the existence of a moral and explanatory strength to use the multi-linear regression model between the independent variables (internal training, motivation and Rewards, internal communication, empowerment, organization culture)

\subsection{Reliability and Validity Assessment}

Table 7 shows Cronbach coefficient alpha values, which measures the internal consistency for the whole model was estimated at 0.92 , while it was 0.85 for the internal training, 0.81 for motivation and rewards, 0.78 for internal communication, 0.77 for empowerment, 0.82 organization cultures, and 0.82 for employees' performance. All of them are acceptable.

Table 7. Cronbach's coefficient alpha values

\begin{tabular}{ll}
\hline & Cronbach's Alpha \\
\hline Internal Training & .85 \\
Motivation and Rewards & .81 \\
Internal Communication & .78 \\
Empowerment & .77 \\
Organization Culture & .82 \\
Internal marketing & .92 \\
Employees' Performance & .82 \\
\hline
\end{tabular}




\subsection{Correlation Analysis: Relationship between Variables}

Table 8. Correlation coefficients between independent variables (internal training, motivation and rewards, internal communication, empowerment organization culture) and the dependent variables (employees' performance)

\begin{tabular}{lll}
\hline & & Performance Employers' \\
\hline \multirow{2}{*}{ Internal Training } & Pearson Correlation & $.231^{* *}$ \\
& Sig. (2-tailed) & .000 \\
Motivation and Rewards & $\mathrm{N}$ & 333 \\
& Pearson Correlation & $.325^{* *}$ \\
Internal Communication & Sig. (2-tailed) & .000 \\
& $\mathrm{~N}$ & 333 \\
Empowerment & Pearson Correlation & $.251^{* *}$ \\
& Sig. (2-tailed) & .000 \\
Organization Culture & $\mathrm{N}$ & 333 \\
& Pearson Correlation & $.212^{* *}$ \\
Sig. (2-tailed) & .000 \\
internal marketing & $\mathrm{N}$ & 333 \\
& Pearson Correlation & $.599^{* *}$ \\
& Sig. (2-tailed) & .000 \\
& $\mathrm{~N}$ & 333 \\
& Pearson Correlation & $.431^{* *}$ \\
& Sig. (2-tailed) & .000 \\
& $\mathrm{~N}$ & 333 \\
\hline
\end{tabular}

**Correlation is significant at the 0.01 level (2-tailed).

Table 8 shows the existence of a positive and statistically significant relation between independent variables (internal training, motivation and rewards, internal communication, empowerment organization culture)

\subsection{Multiple linear Regression Coefficients (Stepwise) Analysis}

The regression coefficients and their statistical significance (stepwise) were calculated for each statistically significant independent variable. Table 9 shows a summary of multiple linear regression analysis of the model.

Table 9. Model summary of multiple linear regression analysis and regression coefficients

\begin{tabular}{|c|c|c|c|c|c|c|c|c|}
\hline \multirow{2}{*}{\multicolumn{2}{|c|}{ Model }} & & & \multicolumn{2}{|c|}{ Unstandardized Coefficients } & \multirow{2}{*}{$\begin{array}{l}\text { Standardized Coefficients } \\
\text { Beta }\end{array}$} & \multirow{2}{*}{$\mathrm{t}$} & \multirow{2}{*}{ Sig. } \\
\hline & & & & $\mathrm{B}$ & Std. Error & & & \\
\hline \multirow{3}{*}{2} & \multicolumn{3}{|c|}{ (Constant) } & 1.001 & .211 & & $* 4.754$ & .000 \\
\hline & \multicolumn{3}{|c|}{ Organization Culture } & .588 & .050 & .559 & $* 11.705$ & .000 \\
\hline & \multicolumn{3}{|c|}{ Motivation and Rewards } & .114 & .054 & .101 & $* 2.111$ & .035 \\
\hline \multicolumn{2}{|c|}{ Model } & $\mathrm{R}$ & R Square & \multicolumn{2}{|c|}{ Adjusted R Square } & Std. Error of the Estimate & \multicolumn{2}{|c|}{ R Square Change } \\
\hline \multicolumn{2}{|l|}{1} & $.599^{\mathrm{a}}$ & .359 & \multicolumn{2}{|c|}{.357} & .58867 & \multicolumn{2}{|l|}{.359} \\
\hline \multicolumn{2}{|l|}{2} & $.606^{\mathrm{b}}$ & .368 & \multicolumn{2}{|l|}{.364} & .58562 & \multicolumn{2}{|l|}{.009} \\
\hline
\end{tabular}

a. Dependent Variable: Performance Employers'.

b. Predictors: (Constant), Organization Culture.

c. Predictors: (Constant), Organization Culture, Motivation and Rewards.

It can be seen from Table 9 that the value of multi-correlation coefficient between independent variables is 
(0.606), and that the value of total coefficient of determination $\left(\mathrm{R}^{2}\right)$ is $(0.368)$. The value of the coefficient of determination total average (adjusted $\mathrm{R}^{2}$ ) is $(0.364)$, which indicates that the two independent variables altogether have been able to explain $(36.8 \%)$ of the changes occurring in the dependent variable as can be seen from the following table (employees' performance), while the rest of changes are due to other factors as seen in the table, which are as follows:

The existence of a statistically significant coefficient linear regression, standard and non-standard associated with the independent (organization culture), where the value was $(\mathrm{t}=11.705)$ with a statistically significance $(0.000)$ which is lower than the level of statistical significance $(\alpha=0.05)$, indicating the rejection of the null hypothesis and the acceptance of the alternative, which states that "There is effect for the organization culture on employees' performance". So, there is significance for standard linear regression equation coefficient, which amounted to value (0.559), and non-standard (0.588). And table (9) shows that the independent variable (Organization Culture) came in first place, where it alone explained about (35.9\%) of variance of the dependent variable (Employees' Performance).

The existence of a statistically significant coefficient linear regression, standard and non-standard associated with the independent (motivation and rewards), where the value was $(\mathrm{t}=2.011)$ with a statistically significance (0.035) which is lower than the level of statistical significance $(\alpha=0.05)$, indicating the rejection of the null hypothesis and the acceptance of the alternative, which states that "There is effect for the motivation and rewards on employees' performance". So, there is significance for standard linear regression equation coefficient, which amounted to value (0.101), and non-standard (0.114) and table (8) shows that the independent variable (motivation and rewards) came in second place, where it alone explained about $(0.9 \%)$ of variance of the dependent variable (Employees' Performance).

\subsection{Factor Analysis}

Factor analysis has been done using "principal component analysis" variables of the questionnaire related to "internal marketing" were rotated approximated through "Varmax". Eigenvalue has used one as a minimum value to accept the factor. Factor analysis has resulted in five factors, which are: internal training with a variance of 70.398, motivation and rewards with a variance of 50.120, internal communication with a variance of 61.126 , empowerment with a variance of 52.819, and organization culture with a variance of 55.110. Factor analysis was also done using "principle component analysis" and the variables of the part of the questionnaire related to employees performance were rotated through "Varmax". Eigenvalue has used one as a minimum value to accept the factor; this factor analysis has resulted in one factor with a variance of 55.354.

The following Table (Table 10) shows the results of coefficients analysis for the parts of each dimension of the two measures, the independent and the dependent, as follows:

Table 10. Factor analysis for (internal marketing, performance employers')

\begin{tabular}{|c|c|c|}
\hline Subscale & Item & Loading \\
\hline \multirow{13}{*}{ Internal Training } & Cronbach's Alpha $=0.85$, K.M.O $=0.812$, Total Variance Explained $=70.398$ & \\
\hline & a1 & 0.75 \\
\hline & a2 & 0.73 \\
\hline & a3 & 0.54 \\
\hline & a4 & 0.73 \\
\hline & a5 & 0.83 \\
\hline & a6 & 0.71 \\
\hline & a7 & 0.65 \\
\hline & a8 & 0.72 \\
\hline & a9 & 0.69 \\
\hline & a10 & 0.55 \\
\hline & a11 & 0.72 \\
\hline & a12 & 0.82 \\
\hline \multirow{5}{*}{$\begin{array}{l}\text { Motivation } \\
\text { Rewards }\end{array}$} & Cronbach's Alpha $=0.81$, K.M.O $=0.776$, Total Variance Explained $=50.120$ & \\
\hline & a13 & 0.51 \\
\hline & a14 & 0.54 \\
\hline & a15 & 0.51 \\
\hline & a16 & 0.48 \\
\hline
\end{tabular}




\begin{tabular}{|c|c|c|}
\hline & a17 & 0.63 \\
\hline & a18 & 0.47 \\
\hline & a19 & 0.48 \\
\hline & $\mathrm{a} 20$ & 0.60 \\
\hline & a21 & 0.45 \\
\hline & a22 & 0.48 \\
\hline & a23 & 0.37 \\
\hline & Cronbach's Alpha $=0.78$, K.M.O $=0.767$, Total Variance Explained $=61.126$ & \\
\hline & a24 & 0.58 \\
\hline & a25 & 0.66 \\
\hline Internal & a26 & 0.58 \\
\hline Communication & a27 & 0.47 \\
\hline & $\mathrm{a} 28$ & 0.62 \\
\hline & a29 & 0.68 \\
\hline & a30 & 0.68 \\
\hline & Cronbach's Alpha $=0.77$, K.M.O $=0.775$, Total Variance Explained $=52.819$ & \\
\hline & a31 & 0.51 \\
\hline & a32 & 0.58 \\
\hline & a33 & 0.58 \\
\hline Empowerment & a34 & 0.52 \\
\hline & a35 & 0.47 \\
\hline & a36 & 0.32 \\
\hline & a37 & 0.66 \\
\hline & a38 & 0.58 \\
\hline & Cronbach's Alpha $=0.82$, K.M.O $=0.793$, Total Variance Explained $=55.110$ & \\
\hline & a39 & 0.64 \\
\hline & $\mathrm{a} 40$ & 0.68 \\
\hline & $\mathrm{a} 41$ & 0.47 \\
\hline Oroanization Culture & $\mathrm{a} 42$ & 0.51 \\
\hline Organization Cuiture & $\mathrm{a} 43$ & 0.51 \\
\hline & a44 & 0.60 \\
\hline & $\mathrm{a} 45$ & 0.65 \\
\hline & a46 & 0.46 \\
\hline & a47 & 0.45 \\
\hline & Cronbach's Alpha $=0.82$, K.M.O $=0.822$, Total Variance Explained $=55.354$ & \\
\hline & b1 & 0.50 \\
\hline & b2 & 0.60 \\
\hline & b3 & 0.69 \\
\hline Employees' & b4 & 0.62 \\
\hline Performance' & b5 & 0.43 \\
\hline & b6 & 0.51 \\
\hline & b7 & 0.58 \\
\hline & $\mathrm{b} 8$ & 0.51 \\
\hline & b9 & 0.56 \\
\hline
\end{tabular}

\section{Recommendation}

Depending on the findings of the study the following recommendations are proposed. First, there is a need to direct the administration at all levels to have more interest in all dimensions of internal marketing which employees can apply as internal marketing has clear impact on their performance and on the success of private hospitals in Jordan. Second, concentration of the Jordanian private hospital sector development program should be on the internal market which can improve the performance of their employees to serve customers effectively. Third, focus must be given to the culture prevailing in the hospital sector since it has proven its highly effective influence on employees' performance, and improvement of their work. Fourth, a culture within the organization characterized by creativity and innovation must be built, and it should be different from traditional ones so that 
the level of employees' performance is raised. Fifth, attention to incentives and rewards offered to workers in the Jordanian private hospitals sector should increase since it influences the performance at work. Sixth, hospital sector must pay more attention on the diversification of the system of incentives based on the requirements of workers. Seventh, the private hospital sector should have more concern regarding the repetition of incentives for workers to further encourage them, which will improve their level of performance at work. Eight, administration at the private Jordanian hospitals sector must be encouraged to pay more attention to training due to its importance in the improvement of the employees' performance of development of their methods of work. This can be reflected in the quality of services provided to customers, and more importantly because Jordanian private hospitals have become a popular destination for many customers from outside Jordan. Quality of service provided to people from outside Jordan, Arabs or non-Arabs shall contribute to raising the level of the national income. Ninth, training courses workers need must be studied as they leads to the creation of external customer satisfaction. Tenth, internal communication ties between workers also need to be strengthened as they facilitate the transfer and access of information among employees, which will reflect on their performance. Eleventh, attention should be paid to the contribution of all levels employees in the private Jordanian hospitals sector to decision-making, to developing appropriate marketing strategies, dealing with employees in full transparency, listening to their views and suggestions, so that they contribute to the success of these decisions. Twelfth, the private hospital sector in Jordan needs to apply and follow internal marketing system that commensurate with the nature of their employees and the quality of its customers. Thirteenth, this sector to focus on middleadministrative-category workers due to the importance of their role in customer service provided for local and foreign customers.

\section{References}

Abu, N., \& Mohammed, A. A. (2012). Advanced Marketing. Aldar Aljamiya Alexandria-Egypt.

Ahmad, A. (2012). The Impact of Internal Marketing on NPD, (new product development). Qatar University-College of Business and Economics-Management and Marketing Department.

AlaEdin, M. K. A. (2012). Impact of internal Marketing on Job Satisfaction and Organizational Commitment- A study of Teaching Hospitals in Saudi Arabia. King Abbdulaziz University, Jeddah, Kingdom of Saudi Arabia, September.

Albornouti, S. N. (2000). Human resources management. Dar Wael for publication, Amman, Jordan.

Aldmour, H. H. (2005). Marketing services. Dar Wael for Publication and Distribution, Amman, Jordan.

AlJariri, S. O. K. (2006). The impact of internal marketing and service quality on customer satisfaction: An Empirical Study of a sample of Yemeni banks. A Doctoral thesis in Business Administration, University of Damascus, Syria.

Alkalaldeh, T. M. (2013). Contemporary trends in the development and management of human resources. Dar Albidaya for publication.

Alsahen, M. F. (2002). Readings in Marketing Management. Aldar Aljamiya Alexandria-Egypt.

Altai, H. A. N. (2012). Collaborative relationship between intelligence marketing and internal marketing analysis and their impact on the satisfaction of the employees in the Alselsela hotels (a case study on Amman). AlZitouna University, Faculty of Economics and Administrative Sciences, Amman - Jordan.

De Jager, J. W., \& Swanepoel, S. (2008). Internal Marketing Strategy Focusing on Staff Orientation in Health Care in South Africa. Tshwane University of Technology.

Dunmore, M. (n.d.). Inside-Out Marketing, how to create on internal marketing strategy. London (UK): Kagan Page,

Hashmi, A. (2014). The role of marketing in improving the quality of health services in private institutions. University of Qasidi Merbah, Algeria.

Hawwaorh, A. S. S., \& Sabih, Y. (2011). The impact of internal marketing in customer loyalty through job satisfaction (The cities of Nablus and Jenin). Alnajah National University-Nablus-Palestine

Hossein, V. D., \& Sima, H. (2012). The Effect of Internal Marketing and Organizational Commitment on Banks Success. International Journal of Business and Commerce, 1(9).

Khaleed, H. (2012). Influence of Internal Marketing towards Organizational Performance with Mediating Role of Organizational Competences in not for Profit Organization AIESEC. Faculty of Economics and Business, Indonesia. 
Khanza, Z., Neelum, J., \& Asma, A. S. B. (2012). Impact of Internal Marketing on Market Orientation and Business Performance. International Journal of Business and Social Sciences, 3(12).

Labed, A. I., \& Ryan, O. A. R. (2013). The impact of internal marketing on the performance of employees in civil society organizations. The Islamic University, Amman-Jordan.

Lovelock \& Wirtz. (2006). Service Marketing: People, Technology, Strategy. UK: Pearson-Prentice-Hall.

Luliane \& Cetina, A. P. (2012). Employee Satisfaction Measurement-Part of Internal Marketing. Review of International Comparative Management, 13(1).

Muhammad, A. A. A. (2004). Recent trends to measure and evaluate the performance of staff. Munshaat Almaref, Alexandria.

Nese, A., Mustafa, S., Ali, B., \& Tuncay, A. (2012). The Effect of Internal Marketing on the Performance of Employee and the Mediating Role of Organizational Commitment. Institute for education and research.

Rong, C., \& Guoliang, C. (2013). How internal Marketing Can cultivate Psychological Empowerment and Enhance Employee Performance. Social Behavioral and Personality, 41(4), 529-553. http://dx.doi.org/10.2224/sbp.2013.41.4.529

Seyed, M. M. D. (2012). The Link between Internal Marketing and Human Resources Management. Faculty of Management and Economics, Semnan University, Semnan, Iran.

Yudi, F. (2012). Impact of Internal Marketing on Operational Performance: An American study in low cost carrier industry. International Congress on Interdisciplinary Business and Social Science, http://dx.doi.org/10.1016/j.sbspro.2012.11.219

\section{Copyrights}

Copyright for this article is retained by the author(s), with first publication rights granted to the journal.

This is an open-access article distributed under the terms and conditions of the Creative Commons Attribution license (http://creativecommons.org/licenses/by/3.0/). 